\title{
Comprehensive analysis of the isozyme composition of laccase derived from Japanese lacquer tree, Toxicodendron vernicifluum
}

\author{
Mariko Takano ${ }^{1 *}$ (D, Masaya Nakamura ${ }^{1}$ and Masanobu Tabata ${ }^{2}$
}

\begin{abstract}
We performed an analysis using isoelectric focusing to comprehensively clarify the isozyme composition of laccase derived from Japanese lacquer tree, Toxicodendron vernicifluum. When water extracts of acetone powder obtained from lacquer were subjected to isoelectric focusing, five bands within pl 7.35-9.30 and nine bands within pl 3.50-5.25 were detected using Coomassie staining. Similarly, laccase activity staining using guaiacol showed five bands within pl 7.35-9.30 and three bands within pl 3.50-4.25. However, laccase activity staining using gallic acid showed remarkable staining within pl 3.50-5.85, whereas staining was very weak within pl 7.35-9.30. When the water extracts of acetone powder were fractionated into the fractions containing bands within pl 7.35-9.30 and pl 3.50-5.85 by SPSepharose column chromatography, the former had a blue color and the latter a yellow color. The laccase activity was measured for each of the fractions in buffer solution in the $\mathrm{pH}$ range of 2.5-8.0. When syringaldazine, guaiacol, and 2,6-dimethoxyphenol were used as substrates, the yellow fraction showed considerably higher activity than the blue fraction for pH 5.5-7.5. When 3-methylcatechol and 4-methylcatechol were used as substrates, the yellow fraction showed higher activity for $\mathrm{pH} 4.5-6.5$, and the blue fraction showed higher activity for $\mathrm{pH} 7.0-8.0$. When 2,2'-azinobis(3-ethylbenzothiazoline-6-sulfonic acid) was used as the substrate, both fractions showed maximum activity at optimum pH of 3.0-4.0. Conventionally, in research on blue laccase derived from lacquer, the non-blue fraction corresponding to the yellow fraction lower than pl 6 has been removed during the purification process and thus has not been analyzed. Our results indicated that yellow laccase was present in the non-blue components of lacquer and that it may play a role in urushiol polymerization with previously reported blue laccase.
\end{abstract}

Keywords: Laccase, Toxicodendron vernicifluum, Rhus vernicifera, Yellow laccase, Urushiol

\section{Introduction}

The Japanese lacquer tree (Toxicodendron vernicifluum (Stokes) F. A. Barkl.) is one of the family Anacardiaceae that is widely distributed in East Asia [1]. Lacquer is resin and sap extracted from lacquer trees and has been used since Jomon Period as paint for cultural assets and lacquer wares in Japan, making it a natural material of cultural and social significance $[2,3]$.

\footnotetext{
${ }^{*}$ Correspondence: marin@ffpri.affrc.go.jp

${ }^{1}$ Forestry and Forest Products Research Institute, Tsukuba, Ibaraki 305-8687, Japan

Full list of author information is available at the end of the article
}

The components of lacquer include urushiol, water, plant gum, water-insoluble glycoproteins, and enzymes (laccase, peroxidase, and stellacyanin) $[4,5]$. Urushiol is a generic term for catechol derivatives with an alkyl sidechain that has 15 or 17 carbon atoms at $\mathrm{C}-3$ of the benzene ring; and more than ten types have been reported with different side-chain structures $[4,5]$. Laccase (Lac) is a phenoloxidase and is found widely in plants such as lacquer trees, fungi such as white-rot fungi, and bacteria [6]. Lacquer hardens and dries to form a film, as a result of urushiol becoming oxidatively polymerized by Lac $[4$, 7], and functions as a coating material [8]. Because drying and hardening properties are used as indicators of lacquer quality, Lac has a direct effect on quality [9]. 
Lacquer Lac was the first multicopper oxidase discovered and has been studied in detail in regard to the catalytic mechanisms, functions, properties, and structures of the isolated enzyme [10]. In recent years, detailed analyses of the carbohydrate structure and gene structure of Lacs have been reported [11, 12]. These studies have focused on two to three Lacs with pI 8-10 purified using Reinhammer's method [13]. However, comprehensive isozyme composition and diversity of lacquer Lac remain to be clarified.

In contrast, a wide variety of Lacs have been reported in white-rot fungi [6]. In addition, in white-rot fungi, ligninolytic oxidizing enzymes, including Lac, are known to have many isoenzymes with the same molecular weight but different pIs and these have been analyzed using isoelectric focusing and two-dimensional electrophoresis $[14,15]$.

In this study, we performed a comprehensive analysis of Lac isozymes derived from Japanese lacquer tree using isoelectric focusing.

\section{Materials and methods Samples}

Four samples were used, consisting of "Hatsu-urushi" lacquer collected between mid-June and mid-July 2018 and "Sakari-urushi" lacquer collected between late July and late August, in Ninohe, Iwate Prefecture and Iida, Nagano Prefecture.

\section{Preparation of crude Lac enzymes}

Ten milliliters of each lacquer sample was collected in a $50-\mathrm{mL}$ centrifuge tube, and to this was added $30 \mathrm{~mL}$ of cooled acetone and mixed well. After remaining standing for three days at $-20{ }^{\circ} \mathrm{C}$, the samples were then centrifuged in a refrigerated centrifuge $(13,000 \mathrm{rpm} \times 10 \mathrm{~min})$, and the precipitate was washed with acetone until the supernatant became colorless. The precipitates were then collected and dried at $6{ }^{\circ} \mathrm{C}$ for 3 days to obtain acetone powder. To this was added $15 \mathrm{~mL}$ of distilled water, and extraction was performed in a shaker overnight. After centrifugation to remove insoluble matter, $500 \mathrm{~g} / \mathrm{L}$ of ammonium sulfate was added to the solution, and the mixture was stirred. The solution was again centrifuged to collect blue supernatant, to which ammonium sulfate was added until saturation reached 100\% (767 g/L). The sample was centrifuged, and the supernatant removed to collect blue precipitate. To the blue precipitate, $5 \mathrm{~mL}$ of distilled water was added and dissolved, and after being desalted with a PD-10 column, the sample was concentrated using VIVA SPIN.

\section{Fractionation of Lac}

SP-Sepharose was packed in a column $(1 \mathrm{~cm} \times 10 \mathrm{~cm})$ and equilibrated with phosphate buffer $(\mathrm{pH} 6.0$, $10 \mathrm{mM})$. After crude Lac enzymes were added to the column, $30 \mathrm{~mL}$ of the same phosphate buffer was added, and the eluate was collected (yellow fraction). Then, $20 \mathrm{~mL}$ of phosphate buffer ( $\mathrm{pH} 6.0,300 \mathrm{mM}$ ) was added and the eluate was collected (blue fraction).

\section{Electrophoresis}

Isoelectric focusing was performed using CleanGel IEF and Pharmalyte, broad range $\mathrm{pH} 3.0-9.5$, according to the manufacturer's instructions (Cytiva, Tokyo, Japan).

\section{Staining of the gel}

Proteins separated in the gel were stained using Coomassie Blue R 250. Guaiacol (GU) and gallic acid were used for Lac activity staining.

\section{Measurement of enzymatic activities}

The Lac activity was determined by preparing separate reaction solutions for the different substrates as described below, and measuring the changes in absorbance resulting from substrate oxidation within $1 \mathrm{~min}$ at $25{ }^{\circ} \mathrm{C}$. For GU, $100 \mathrm{mM}$ solution (in $20 \%$ ethanol solution), and for syringaldazine (SA), $1 \mathrm{mM}$ solution (in $100 \%$ ethanol), were prepared. For 3-methylcatechol (3MC), 4-methylcatechol (4MC), and 2,6-dimethoxyphenol (2,6-DMP), $10 \mathrm{mM}$ aqueous solutions were prepared. For 2,2'-azino-bis(3-ethylbenzothiazoline6-sulfonic acid) (ABTS), $40 \mathrm{mg} / \mathrm{L}$ aqueous solution was prepared. As a buffer solution, Mcllvaine buffer ( $\mathrm{pH}$ 2.5-8.0) was used [16]. The samples for which enzyme activity was measured contained $365 \mu \mathrm{L}$ of buffer solution, $25 \mu \mathrm{L}$ of the substrate solution, and $10 \mu \mathrm{L}$ of enzyme sample. Absorbance was measured at wavelengths of $414 \mathrm{~nm}$ for ABTS, $525 \mathrm{~nm}$ for SA, $460 \mathrm{~nm}$ for GU and $477 \mathrm{~nm}$ for 2,6-DMP [17]; absorbance for $3 \mathrm{MC}$ was measured at $430 \mathrm{~nm}$ and $4 \mathrm{MC}$ at $400 \mathrm{~nm}$ as described in "Results".

\section{Instruments}

Multiphor II (Cytiva) was used for electrophoresis. An UV-VIS recording spectrophotometer UV-2400PC (Shimadzu, Kyoto, Japan) was used to measure the enzymatic activity and UV-VIS spectra of lacquer Lac.

\section{Results}

Preparation of crude Lac enzymes

Acetone powder was prepared from each lacquer sample, which was mixed with distilled water to obtain a crude Lac enzyme solution. Table 1 shows the locations 
Table 1 Preparation of crude laccase from lacquer tree

\begin{tabular}{|c|c|c|c|c|c|c|}
\hline Sample no. & Sampling locations & Timing of harvest & $\begin{array}{l}\text { Amount } \\
\text { of lacquer } \\
\text { (g) }\end{array}$ & $\begin{array}{l}\text { Acetone } \\
\text { powder yield } \\
\text { (g) }\end{array}$ & $\begin{array}{l}\text { Total Lac } \\
\text { activity (mAbs/ } \\
\text { min) }\end{array}$ & $\begin{array}{l}\text { Lac activity per gram } \\
\text { of acetone powder } \\
\text { (mAbs/min) }\end{array}$ \\
\hline 1 & Ninohe in Iwate & Late July-late August in 2018 & 34.9 & 0.81 & 568 & 706 \\
\hline 2 & Ninohe in Iwate & Mid-June-mid-July in 2018 & 38.0 & 2.58 & 1679 & 651 \\
\hline 3 & lida in Nagano & Mid-June-mid-July in 2018 & 38.6 & 1.51 & 1541 & 1020 \\
\hline 4 & lida in Nagano & Late July-late August in 2018 & 39.5 & 1.98 & 2972 & 1501 \\
\hline
\end{tabular}

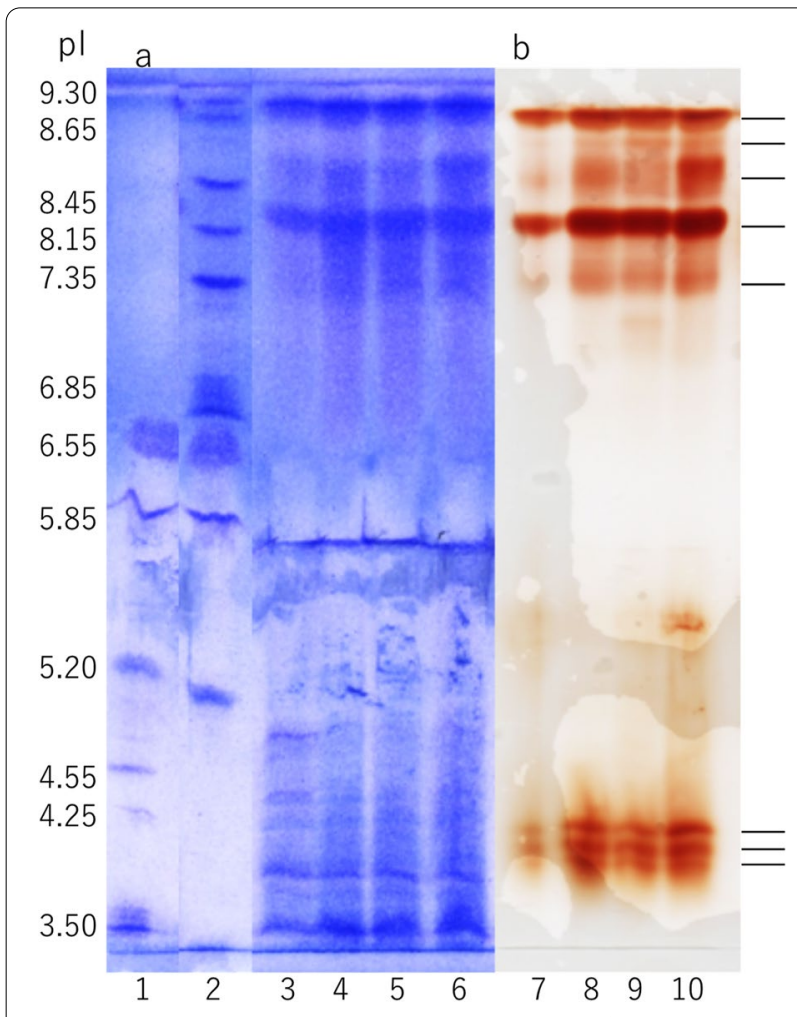

Fig. 1 Isoelectric focusing of water-soluble extracts from acetone powder prepared from the lacquer: a stained with Coomassie Blue $R$ 250; b stained with quaiacol. 1, low pl marker; 2, high pl marker. Lanes 3 to 10 are samples in Table 1. 3, Sample No. 1 in Table 1; 4, No. 2; 5, No. 3; 6, No. 4; 7, No. 1; 8, No. 2; 9, No. 3; 10, No. 4

where the samples were collected, the timings of sample collection, the amounts of samples used, acetone powder yields, the total Lac activities, and the activities per gram of acetone powder. Acetone powder yield and Lac activity varied among the samples.

\section{Isoelectric focusing}

The results of isoelectric focusing on the four crude Lac enzyme samples are shown in Fig. 1. Using Coomassie staining, five bands were detected within pI 7.35and 9.30 and nine bands within pI 3.50-5.20. Similarly, when isoelectric focusing was performed, and Lac activity was determined using GU for $30 \mathrm{~min}$, five bands were detected within pI 7.35-9.30 and three bands within pI 3.50-4.25. All five bands detected within pI 7.359.30 were found to be Lac. However, of the nine bands detected within pI 3.50-5.20, Lac activity was only found in three bands within pI 3.50-4.25.

Regarding the results of isoelectric focusing, the color development was weak in all bands of Sample 1, which had a low total Lac activity (Table 1); however, the positions and relative intensities of bands were the same in all four samples. These results suggest that the type and composition of isozymes and their compositional ratios were similar among all four samples.

In addition, Lac activity staining using gallic acid, following isoelectric focusing of crude Lac enzymes, showed remarkable color development in the bands within $\mathrm{pI}$ $3.50-5.85$, whereas color development was very weak in the five bands within pI 7.35-9.30 (Fig. 2). These results showed that Lac with pI 7.35-9.30 and pI 3.50-5.85 had different character on their enzymatic activity.

\section{Spectral changes of $3 \mathrm{MC}$ and $4 \mathrm{MC}$ oxidized by Lac}

Various aromatic compounds, such as SA, 2,6-DMP, and $\mathrm{GU}$, have been used for measuring Lac activity. In addition to these compounds, two others were used as substrates in this study: $3 \mathrm{MC}$, which has a similar chemical structure to urushiol; and $4 \mathrm{MC}$, which has a similar chemical structure to thitsiol. First, $3 \mathrm{MC}$ and $4 \mathrm{MC}$ were oxidized with Lac to measure their spectral changes during the color development process. Color development by oxidation of 3MC showed a spectrum with a maximum value at $430 \mathrm{~nm}$, and of $4 \mathrm{MC}$ a maximum at $400 \mathrm{~nm}$ (Fig. 3). Accordingly, Lac activity was assayed by measuring absorbance at 430 and $400 \mathrm{~nm}$ for $3 \mathrm{MC}$ and $4 \mathrm{MC}$, respectively.

\section{Activity of crude Lac enzymes}

The activity of crude Lac enzymes extracted from acetone powder was measured in Mcllvaine buffer of $\mathrm{pH}$ 2.5-8.0 [16]. The results for using ABTS, SA, and 2,6-DMP as substrates are shown in Fig. 4a, and for 3MC, 4MC, and 


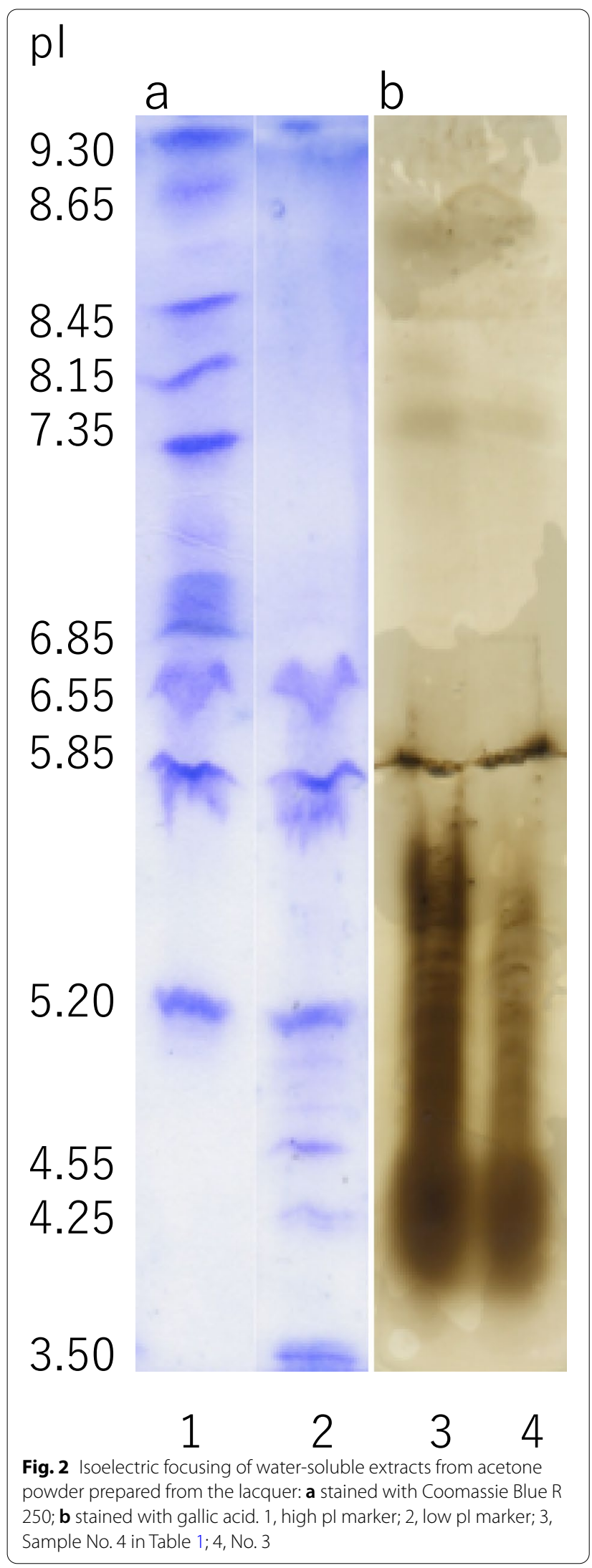

GU in Fig. 4b. The optimum pHs for Lac activity were $\mathrm{pH}$ 3.0-4.0 for ABTS, $\mathrm{pH}$ 6.0-8.0 for SA, and $\mathrm{pH}$ 6.0-7.0 for 2,6-DMP. When $3 \mathrm{MC}, 4 \mathrm{MC}$, and $\mathrm{GU}$ were used as substrates, Lac activity was high at $\mathrm{pH}$ 5.0-8.0. ABTS showed high Lac activity in acidic conditions, whereas the other substrates showed high Lac activity in the neutral to weakly alkaline conditions.

\section{Fractionation of crude Lac enzymes}

As shown in the results described above (Fig. 2), Lac with pI 7.35-9.30 and pI 3.50-5.85 had different character on their enzymatic activity. For analysis of the difference between these two enzymes, crude Lac was fractionated as follows. The Lac samples were separated by SP-Sepharose column chromatography into two fractions: one containing Lac with pI 7.35-9.30 (exhibiting a blue color) and one with pI $3.50-5.85$ (exhibiting a yellow color) (Fig. 5). The blue fraction showed maximum absorption at around $600 \mathrm{~nm}-\mathrm{a}$ characteristic of blue Lac; whereas no maximum absorption was observed around $600 \mathrm{~nm}$ for the yellow fraction (Fig. 6).

\section{Isoelectric focusing of the fractionated samples}

The blue and yellow fractions were subjected to isoelectric focusing, and the results of Coomassie staining and Lac activity staining by GU are shown in Fig. 5. Coomassie staining showed that the blue fraction contained bands within pI 7.35-9.30, and the yellow fraction contained bands within pI 3.50-5.85. When the duration of GU staining was extended to over an hour, the Lac activity was confirmed widely, corresponding to multiple bands within pI 4.25-5.85 in addition to three bands near pI 4 (Fig. 1b). These results suggested that characteristics of Lac activity differed between the blue and yellow fractions.

\section{Lac activity of the fractionated samples}

To compare characteristics of Lac activity between the blue and yellow fractions, Lac activity was measured for each of the substrates within the range of $\mathrm{pH} 2.5-8.0$ (Fig. 7). For comparison of Lac activity of these 2 fractions working in lacquer, Lac activity contained in the same amount of lacquer was assayed.

When $3 \mathrm{MC}$ was used as the substrate, the yellow and the blue fractions exhibited the highest Lac activity at $\mathrm{pH} 6.0$ and 8.0, respectively. At $\mathrm{pH} 4.5-6.0$, the yellow fraction showed higher activity than the blue fraction, and the blue fraction showed higher activity than the yellow at $\mathrm{pH} 7.0-8.0$. For SA, the yellow fraction showed maximum Lac activity at $\mathrm{pH} 6.5$ and the blue fraction at $\mathrm{pH}$ 8.0. In the range of $\mathrm{pH} 5.0-7.5$, the yellow fraction showed higher activity than the blue fraction. For 2,6-DMP, the yellow fraction showed 

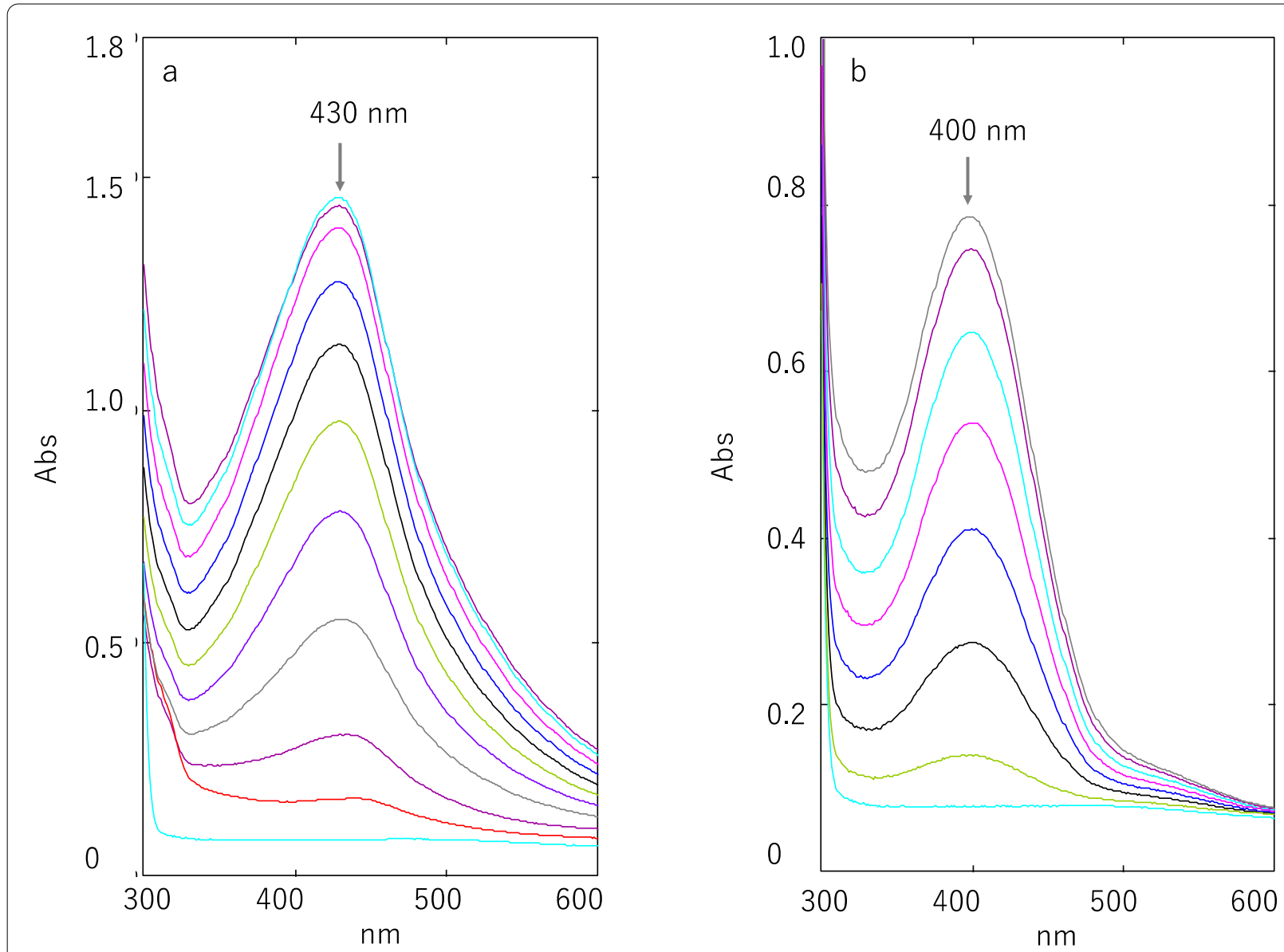

Fig. 3 Spectra change of 3-methylcatechol and 4-methylcatechol oxidized by laccase. Spectral changes were recorded at intervals of 2 min. a $3 \mathrm{MC}$; b $4 M C$
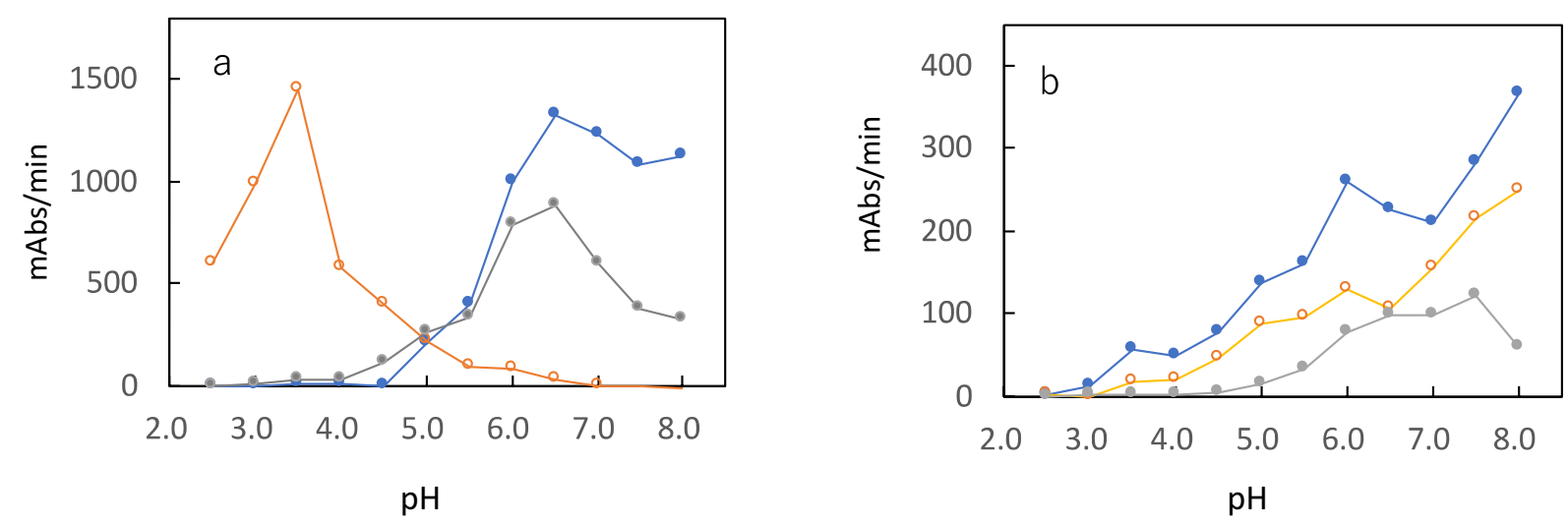

Fig. 4 Laccase activity of water-soluble extracts from acetone powder prepared from the lacquer. a Yellow line shows laccase activity measured with ABTS; blue line, SA; gray line, 2,6-DMP. b yellow line, 4MC; blue line, 3MC; gray line, GU 


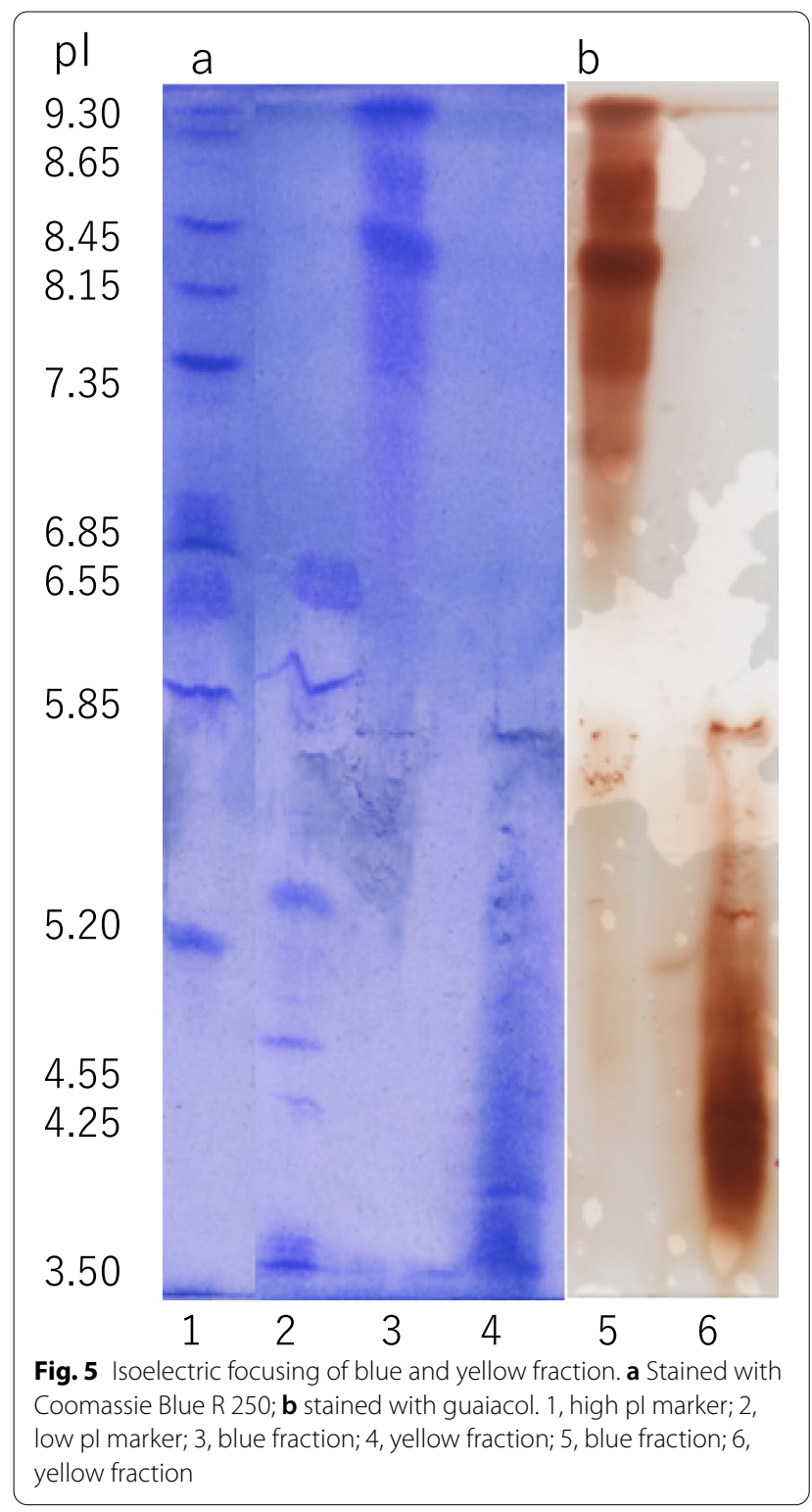

maximum Lac activity at $\mathrm{pH} 7.0$ and the blue fraction at $\mathrm{pH}$ 8.0. The yellow fraction showed higher activity at $\mathrm{pH} 4.5-7.5$ than the blue fraction. For 4MC, the yellow fraction showed maximum Lac activity at $\mathrm{pH}$ 5.0-6.0, and the blue fraction at $\mathrm{pH} 8.0$. The yellow fraction had higher activity than the blue fraction at $\mathrm{pH} 4.5-6.0$, and the blue fraction had higher activity than the yellow at $\mathrm{pH}$ 7.0-8.0. For ABTS, the yellow fraction showed maximum Lac activity at $\mathrm{pH} 3.5$, and the blue fraction at $\mathrm{pH}$ 3.0. At pH 2.5-3.5, the blue fraction had higher activity than the yellow. For GU, the yellow and blue fractions showed maximum Lac activities at $\mathrm{pH} 7.0$ and 8.0, respectively. At pH 5.0-7.5, the yellow fraction showed higher activity than the blue.

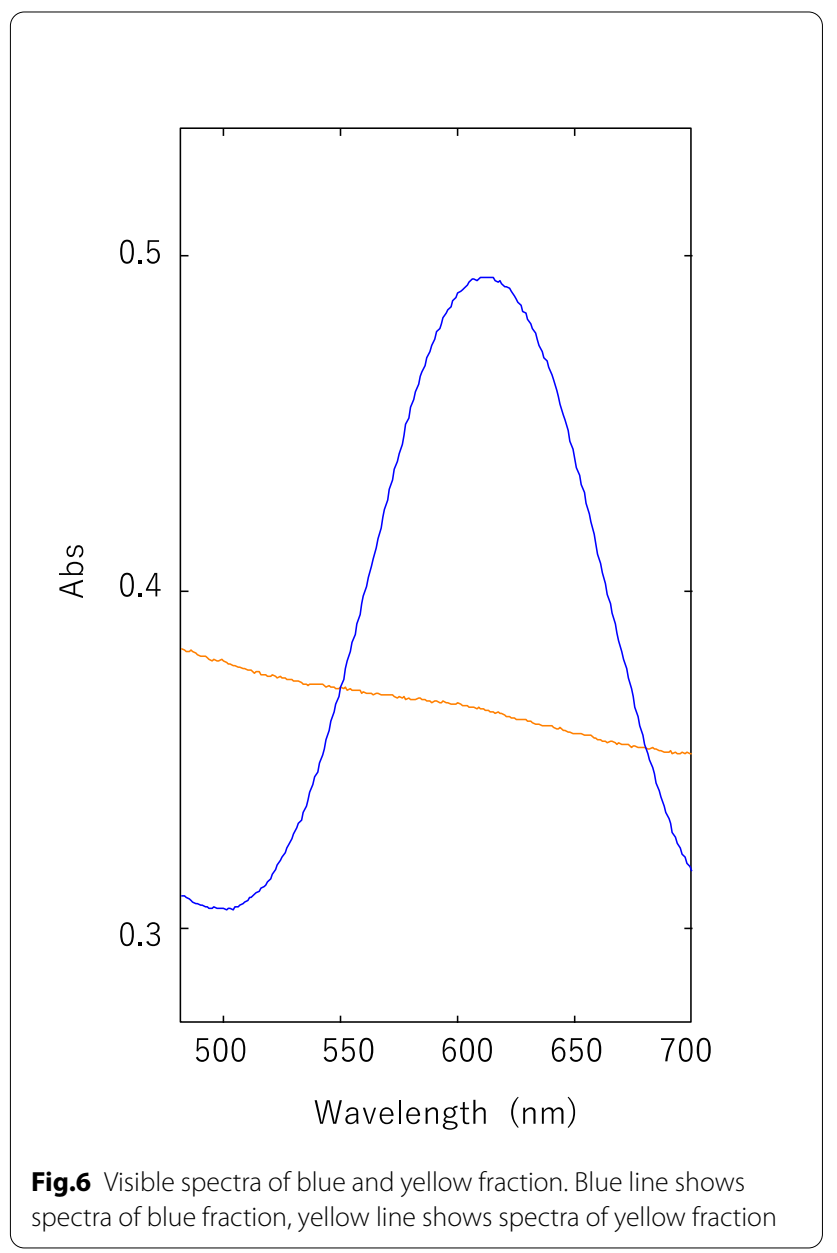

Although the results shown were for Sample No. 4, which had the highest total Lac activity among all samples (Table 1), similar results were obtained for the remaining three samples.

\section{Discussion}

In this study, we performed an analysis using isoelectric focusing to clarify the comprehensive composition of the isozymes of Lac derived from lacquer. Isoelectric focusing performed on crude Lac enzymes that had been extracted from acetone powder showed multiple bands indicating Lac activity detected by GU in the ranges of pI 3.50-5.20 and 7.35-9.30 (Fig. 1). However, laccase activity detected by gallic acid showed remarkable staining within $\mathrm{pI} 3.50-5.85$, whereas staining was very weak within pI 7.35-9.30 (Fig. 2). For elucidating the difference between Lac with pI 3.50-5.85 and 7.35-9.30, crude Lac was fractionated and analyzed. When the crude Lac enzymes were separated into the fractions containing the bands within pI 3.50-5.85 and 7.35-9.30, the latter samples were blue in color and the former were yellow 


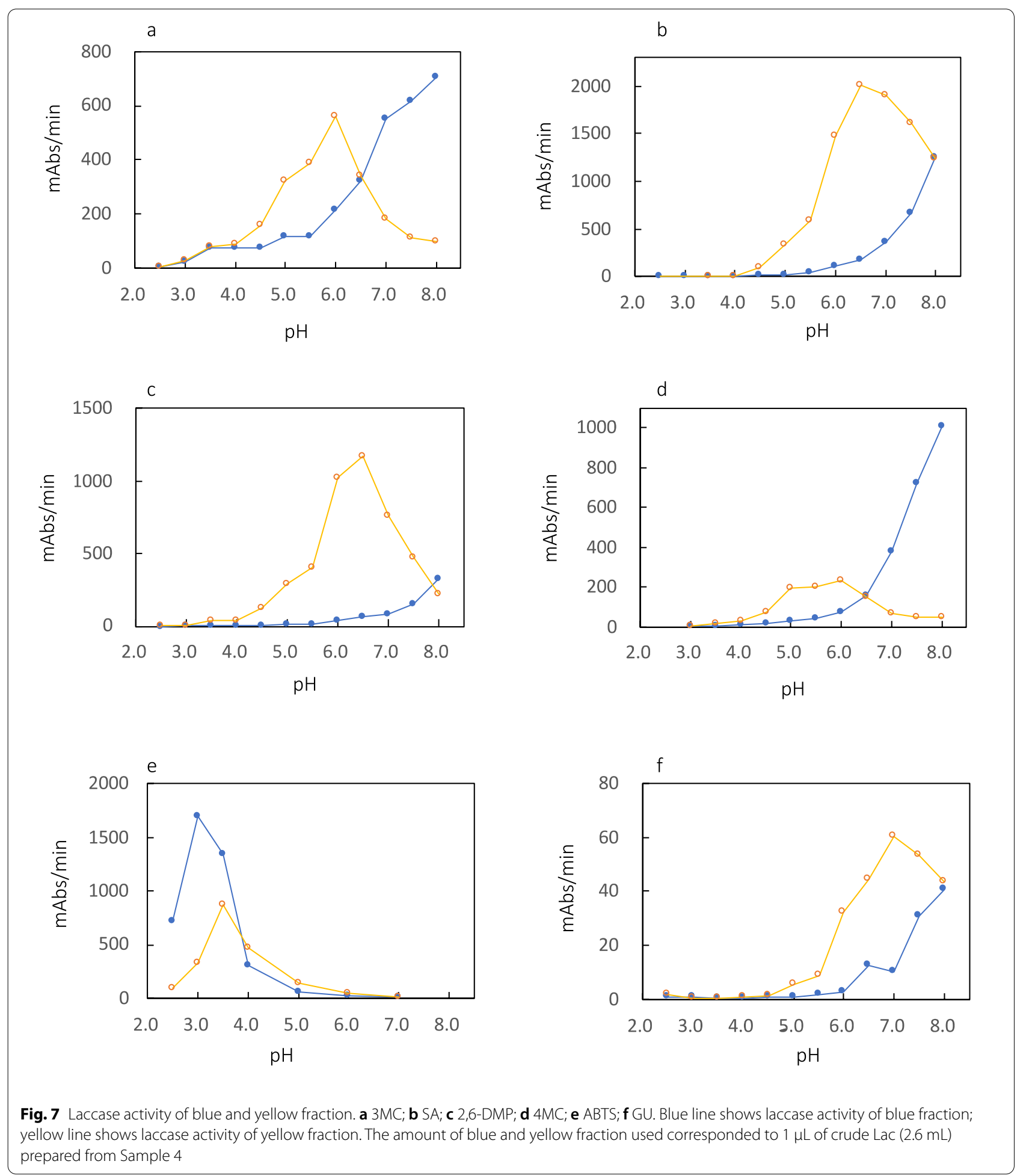

(Fig. 6). The yellow fraction showed Lac activity equal to or higher than the blue fraction (Fig. 7). The yellow fraction is conventionally removed during the purification process of lacquer Lac and has thus seldom been analyzed. This paper is the first to report the importance of the yellow fraction as a component of lacquer Lac.

Lacquer Lac was the first multicopper oxidase found and has long been studied in detail to understand the 
enzyme properties, including structure and functions $[6,10]$. Isoelectric points around pI 8-10 have been reported for purified lacquer Lac, and the enzymes are known to exhibit blue color with a maximum absorbance at around $600 \mathrm{~nm}$ in the UV-VIS spectra [13].

The blue fraction analyzed in this study had a maximum absorbance at around $600 \mathrm{~nm}$ and contained bands within pI 7.35-9.30. These characteristics were consistent with previously reported characteristics of the blue fraction of lacquer Lac. In contrast, the crude Lac enzymes of the yellow fraction had isoelectric points within pI $3.50-5.85$ and showed no distinct maximum absorption at around $600 \mathrm{~nm}$ in the visible spectrum-characteristics not consistent with those of conventional blue Lac (Figs. 5, 6).

Lacquer Lac has been previously studied for the purpose of analyzing the blue proteins contained in lacquer. Therefore, the non-blue fractions have been removed during the purification of the blue Lac. In many such studies, a purification process that used an ion-exchange resin was set up, and proteins or other components of pI 6.0 or lower were removed $[12,13]$. The Lacs from the bands within pI 3.50-5.85 detected in this study should correspond to the fractions that were previously removed.

There was a large difference in Lac activity for the blue and yellow fractions depending on the type of substrate and $\mathrm{pH}$ (Fig. 7). When SA, 2,6-DMP, and GU were used as substrates, the yellow fraction showed higher activity than the blue fraction in the $\mathrm{pH}$ range of 5.5-7.5. At $\mathrm{pH} 6-7$, especially, Lac activity was mostly derived from the yellow fraction and not the blue fraction. The SA, 2,6-DMP, and GU have been used as versatile substrates to measure the activity of lacquer Lac. The previously reported Lac activity of lacquer acetone powder may have originated from the yellow rather than the blue fraction.

For $3 \mathrm{MC}$ and $4 \mathrm{MC}$, the yellow fraction showed higher activity than the blue fraction at $\mathrm{pH} 4.5-6.5$, and the blue fraction showed higher activity than the yellow at pH 7.0-8.0. Compared with SA, 2,6-DMP, and GU, 3MC has a higher structural similarity to urushiol (Fig. 8). The results suggest that in the polymerization of urushiol, the blue and yellow fractions acted complementarily over a wide $\mathrm{pH}$ range.

When ABTS was used as the substrate, significant differences in Lac activity were observed compared to other substrates. The optimum $\mathrm{pH}$ of lacquer Lac has been reported to be $\mathrm{pH}$ 5.0-8.0 when SA is the substrate [6, 18]. In this study, when SA, 2,6-DMP, 3MC, $4 \mathrm{MC}$, and GU were used as substrates, the optimum $\mathrm{pH}$ was 5.08.0. However, when ABTS was the substrate, both the blue and yellow fractions had optimum $\mathrm{pH}$ of 3.0-4.0.
ABTS is widely used as a substrate to measure activity of Lac and peroxidases. The other substrates used had a skeleton similar to the structure of wood components; however, ABTS had a different chemical structure. The Lac of white-rot fungi is considered to have an acidic optimum $\mathrm{pH}$ [6]; however, in recent years, studies on yellow and white Lac derived from white-rot fungi have reported that optimum $\mathrm{pH}$ of $\mathrm{SA}$ is $\mathrm{pH} 6-7$, whereas optimum $\mathrm{pH}$ of ABTS is in the range of $\mathrm{pH} 3-4$ [19, 20].

The color development test following isoelectric focusing that used gallic acid confirmed strong color development in multiple bands within pI 3.5-5.85 of the yellow fraction, whereas color development was weak in the five bands within pI 7.35-9.30 of the blue fraction.

The GU color development test performed on the yellow fraction confirmed Lac activity in multiple bands within $\mathrm{pI} 4.25-5.85$, in addition to three bands within $\mathrm{pI}$ $3.50-4.25$, by extending the reaction time. However, as the reaction time for the Lac activity measurement was shorter than $5 \mathrm{~min}$, it was likely that the three bands that developed color in this short time contributed to the reaction.

All these results indicated that the yellow fraction was at least as important as the blue fraction as a Lac component of lacquer.

Lac is a multicopper oxidase, and the active center responsible for its catalytic function is composed of four copper atoms, which are classified into types I, II, and III [10]. Among them, it has become clear that type I contributes to development of the blue color. An earlier analysis of lacquer Lac reported that removing copper from Lac resulted in decreased enzyme activity and loss of the blue color [21].

In this study, although the bands within pI 3.5-5.2 contained in the yellow fraction were very low in amount and intensity compared to the bands within pI 7.35-9.30, the bands were very clear and were not smeared as often occurs due to degeneration of the protein (Fig. 1). In addition, as discussed earlier, the yellow fraction showed a Lac activity equal to or greater than the blue fraction, with no results indicating deactivation of the enzyme (Fig. 7). Therefore, it is unlikely that the deterioration or degradation of the blue fraction resulted in the deterioration or loss of type I copper and that the loss of blue color gave rise to the yellow fraction. These results indicated that the yellow fraction represented a completely different enzymatic protein from the blue fraction. In whiterot fungi, multiple isozymes of Lac have been reported, including yellow and white Lac, which do not exhibit blue color $[17,22,23]$. Our results indicated that yellow Lac was also present in lacquer. 


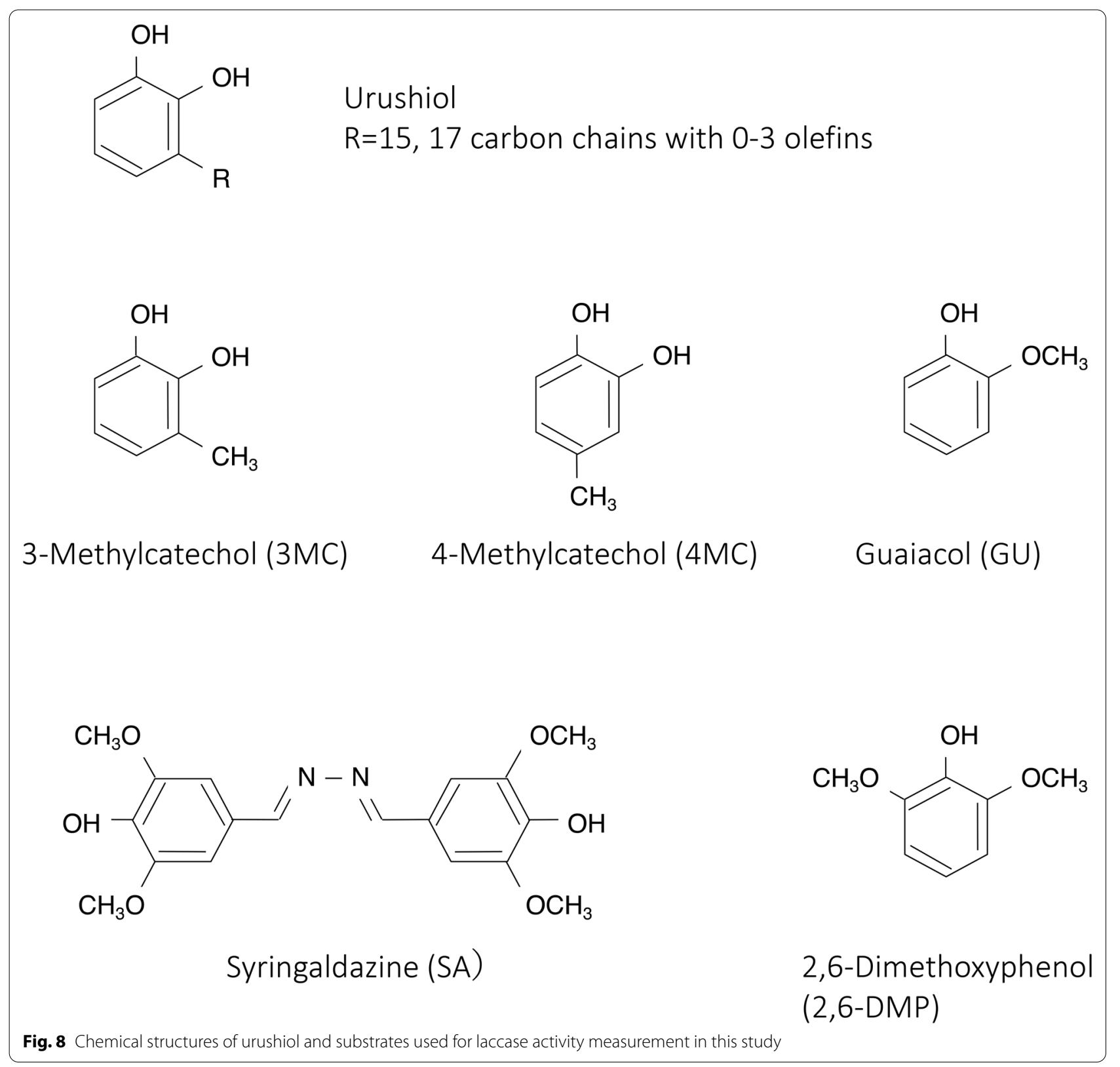

\section{Conclusions}

In this study, we comprehensively analyzed lacquer Lac using isoelectric focusing and found multiple Lacs not previously described. Among them, more than one Lac enzyme with an isoelectric point within pI 3.5-5.85 was suggested to be yellow Lac, which did not exhibit a blue color. Enzymatic activity was measured for the isolated blue and yellow fractions at $\mathrm{pH}$ 2.5-8.0 using several substrates, showing that the yellow fraction had an activity equal to or greater than the blue fraction. These results indicated that there were multiple
Lac enzymes in lacquer that could be involved in the polymerization and drying of urushiol, in addition to the blue Lacs that have been commonly studied.

\section{Abbreviations}

Lac: Laccase; GU: Guaiacol; SA: Syringaldazine; 3MC: 3-Methylcatechol; 4MC: 4-Methylcatechol; 2,6-DMP: 2,6-Dimethoxyphenol; ABTS: 2,2'-Azino-bis(3ethylbenzothiazoline-6-sulfonic acid).

\section{Acknowledgements}

The authors thank Mr. Masayuki Seko and Mr. Yoshihiro Takeuchi for collecting the lacquer. 


\section{Authors' contributions}

MT, MN, MT conceived, planned the work leading to the report. MT performed most of the experiments and interpreted the evidence. All authors read and approved the final manuscript.

\section{Funding}

This work was supported by Japan Society for the Promotion of Science, Gant Number $19 \mathrm{H} 00551$.

\section{Availability of data and materials}

All data generated or analyzed during this study are included in this published article.

\section{Ethics approval and consent to participate}

Not applicable.

\section{Consent for publication}

Not applicable.

\section{Competing interests}

The authors declare that they have no competing interests.

\section{Author details}

${ }^{1}$ Forestry and Forest Products Research Institute, Tsukuba, Ibaraki 305-8687, Japan. ${ }^{2}$ Tohoku Research Center, Forestry and Forest Products Research Institute, Morioka, Iwate 020-0123, Japan.

Received: 15 October 2020 Accepted: 18 January 2021

Published online: 26 January 2021

\section{References}

1. Suzuki M, Yonekura K, Noshiro S (2007) Distribution and habitat of Toxicodendron vernicifluum (Stokes) F. A. Barkl. (Anacardiaceae) in China. Jpn J Histor Bot 15:58-62

2. Miyamoto M, Kakuda A (2008) An exhibition of Shisui Rokkaku, who established Japanese 'National Treasure'. Executive committee on an exhibition of Shisui Rokkaku. pp. 82-111

3. Snyder DM (1989) An overview of oriental lacquer. J Chem Educ 66:977-980

4. Kumanotani J (1995) Urushi (oriental lacquer) - a natural aesthetic durable and future-promising coating. Prog Org Coat 26:163-195

5. Kamiya Y, Miyakoshi T (2001) Synthesis of urushiol components and analysis of urushi sap from Rhus vernicifera. J Oleo Sci 50:865-874

6. Madhavi V, Lele SS (2009) Laccase: properties and applications. BioResources 4:1694-1717

7. Lu R, Harigaya S, Ishimura T, Nagase K, Miyakoshi T (2004) Development of a fast drying lacquer based on raw lacquer sap. Prog Org Coat 51:238-243

8. Kamiya Y, Niimura Y, Miyakoshi T (2000) Evaluation of synthesized lacquer films using pyrolysis-gas chromatography/mass spectrometry. Bull Chem Soc Jpn 73:2621-2626
9. Japanese Standards Association (1979) JIS K5950-1979 refined rhus lacquer. Japanese Standards Association, Tokyo

10. Solomon El, Sundaram UM, Machonkin TE (1996) Multicopper oxidases and oxygenases. Chem Rev 96:2563-2605

11. Tumurbaatar $O$ (2015) Enzymatic digestion and mass spectroscopies of $\mathrm{N}$-linked glycans in lacquer stellacyanin and laccase from Rhus vernicifera. Dissertation, Kitami institute of Technology. https://doi.org/10.19000 100008428

12. Nitta K, Kataoka K, Sakurai T (2002) Primary structure of a Japanese lacquer tree laccase as a prototype enzyme of multicopper oxidases. J Inorg Biochem 91:125-131

13. Reinhammar B (1970) Purification and properties of laccase and stellacyanin from Rhus vernicifera. Biochim Biophys Acta 205:35-47

14. Leisola MSA, Kozulic B, Meussdoerffer F, Fiechter A (1987) Homology among multiple extracellular peroxidases from Phnerochaete chrysosporium. J Biol Chem 262:419-424

15. Lobos S, Larraín J, Salas L, Cullen D, Vicuña R (1994) Isoenzymes of manganese-dependent peroxidase and laccase produced by the lignindegrading basidiomycete Ceriporiopsis subvermispora. Microbiology 140:2691-2698

16. Mcllvaine TC (1921) A buffer solution for colorimetric comparison. J Biol Chem 49:183-186

17. Palmieri G, Giardina P, Bianco C, Scaloni A, Capasso A, Sannia G (1997) A novel white laccase from Pleurotus ostreatus. J Biol Chem 272:31301-31307

18. Lu R, Honda T, Sung M, Jung J, Miyakoshi T (2017) Analysis of fresh sap collected from Ryukyu lacquer tree. Anal Sci 33:1253-1257

19. Ike PTL, Moreira AC, Almeida FG, Ferreira D, Birolli WG, Porto ALM, Souza DHF (2015) Functional characterization of a yellow laccase from Leucoagaricus gongylophorus. Springerplus 4:654. https://doi.org/10.1186/ s40064-015-1464-y

20. Pozdnyakova NN, Turkovskaya OV, Yudina EN, Rodakiewicz-Nowak Y (2006) Yellow laccase from the fungus Pleurotus ostreatus D1: purification and characterization. Appl Biochem Microbiol 42:56-61

21. Omura T (1961) Studies on laccases of lacquer trees. III Reconstruction of laccase from its protein and copper. J Biochem 50:389-393

22. Leontievsky AA, Vares T, Lankinen P, Shergill JK, Pozdnyakova NN, Myasoedova NM, Kalkkinen N, Golovleva LA, Cammack R, Thurston CF, Hatakka A (1997) Blue and yellow laccases of ligninolytic fungi. FEMS Microbiol Lett 156:9-14

23. Daroch M, Houghton CA, Moore JK, Wilkinson MC, Carnell AJ, Bates AD, Iwanejko LA (2014) Glycosylated yellow laccases of the baisidomycete Stropharia aeruginosa. Enzyme Microb Technol 58-59:1-7

\section{Publisher's Note}

Springer Nature remains neutral with regard to jurisdictional claims in published maps and institutional affiliations.

\section{Submit your manuscript to a SpringerOpen ${ }^{\circ}$ journal and benefit from:}

- Convenient online submission

- Rigorous peer review

- Open access: articles freely available online

- High visibility within the field

- Retaining the copyright to your article

Submit your next manuscript at springeropen.com 